\title{
Abnormal placentation at a tertiary care centre
}

\section{Suman S. Sharma*, Ashish V. Gokhale, Shonali Agarwal, Jaydip Hindocha, Ashini Kondhia}

Department of Obstetrics and Gynecology, Baroda Medical College, Vadodara, Gujarat, India

Received: 01 July 2020

Accepted: 08 August 2020

\section{*Correspondence:}

Dr. Suman S. Sharma,

E-mail: sharmasuman29@gmail.com

Copyright: () the author(s), publisher and licensee Medip Academy. This is an open-access article distributed under the terms of the Creative Commons Attribution Non-Commercial License, which permits unrestricted non-commercial use, distribution, and reproduction in any medium, provided the original work is properly cited.

\section{ABSTRACT}

Background: Placentation abnormalities such as placenta previa, placenta accreta and vasa previa are associated with antepartum and postpartum haemorrhage, which makes them an important cause of serious fetal and maternal morbidity and even mortality in India. In spite of the significant improvement in obstetric care and management and modern transfusion service, antepartum and postpartum bleeding continues to be a significant cause of very high-risk pregnancy.

Methods: This is a retrospective study conducted in department of obstetrics and gynecology, Sir Sayaji Hospital, Baroda, for a period of 2 years from January 2018 to December 2019. All cases of placenta previa and morbidly adherent placenta admitted during pregnancy in this period were included in the study. All case records were obtained and carefully analysed to find out the incidence, various types of placenta previa and adherent placenta, its clinical presentation and its outcome in relation to mode of delivery, birth weight, maternal and perinatal morbidity and mortality.

Results: The prevalence of placenta previa was $0.87 \%$ and was more commonly present among multigravida women (80.3\%). Most common type of placenta previa was type 1 in 51 cases (35.9\%) cases followed by type 2 in 33 cases (23.2\%). 29 cases (20.4\%) were of complete placenta. Morbidly adherent placenta comprised $4.2 \%$. Single case $(0.7 \%)$ was of vasa previa. Out of 142 cases, $12(8.4 \%)$ had atonic PPH and $8(5.6 \%)$ cases underwent peripartum hysterectomy, (12.6\%) 18 patients had hemorrhagic shock due to severe blood loss. All cases of perinatal mortality were between 28 to 30 weeks weighing between 1-1.2 kg associated with complete placenta previa in 14 cases and type 3 (incomplete) in 8 cases. There was no maternal mortality in this study

Conclusions: Abnormal placentation carries a very high-risk for maternal and fetal outcome. Anticipation, prevention, early detection and appropriate management will result in favorable outcome and will boost the present scenario of management of high-risk pregnancies.

Keywords: Morbidity, Placenta accreta, Placenta previa, Transfusion

\section{INTRODUCTION}

Placentation abnormality involves a spectrum of condition that includes placenta previa, placenta accreta and vasa previa. These conditions are categorized in high risk pregnancy as all associated with antepartum and post-partum haemorrhage, which makes them an important cause of serious fetal and maternal morbidity and even mortality. Abnormal placentation involves the attachment of placental villi directly to the myometrium with potentially deeper invasion into the uterine wall or surrounding organs. ${ }^{1}$ Placenta previa is defined as situation of the placenta partially or wholly in the lower uterine segment of the uterus. In systematic reviews, the pooled prevalence of placenta previa is approximately 4 per 1000 births but varies worldwide. ${ }^{2}$ The prevalence is several folds higher around 20 weeks of gestation (as high as 2 percent) than at birth because most previas identified early in pregnancy resolve before delivery.

Placenta accrete spectrum (PAS) is a group of disorder ranging from abnormally adherent to deeply invasive 
placental tissue. The median prevalence of placenta previa was $0.56 \%$ whereas the median prevalence of placenta previa with PAS was $0.07 \%$. The incidence of PAS in women with a placenta previa was $11.10 \% .^{3}$

Vasa previa is a condition in which blood vessels within the placenta or the umbilical cord are trapped between the fetus and the internal os of cervix, mean incidence of VP of 0.60 per 1000 pregnancies. $^{4}$

Abnormality of decidualization either by trauma or deficiency of decidua, as in cases of placenta previa implanting in the lower uterine segment or caesarean scar, is the common factor in the etiology of abnormal placentation.

The pathogenesis for accreta syndrome seems to involve an abnormal interaction between the decidua and the invasive extra-villous trophoblast, leading to failure of maternal tissues to restrain the invading trophoblast.

The early identification of previa and PAS helps in managing the condition and increasing the chances of better pregnancy outcome. Ultrasonography is the modality of choice for investigation.

Ultrasonographic localization and doppler studies in morbidly adherent placenta shows the following feature ${ }^{5}$ :

- Placenta previa

- Placental lacunae with turbulent flow

- Irregular bladder wall with extensive associated vascularity

- Loss of retroplacental clear spaces

- Myometrial thickness <1 mm or loss of visualization of the myometrium.

Gap in the retroplacental blood flow. Any factors that may lead to damage and scaring of the endometrium is considered as risk factor. For e.g.:

- Previous caesarean delivery or uterine surgery

- Increased number of prior cesareans - multiple uterine scar

- Prior dilation and curettage

- Myomectomies

- Spontaneous or induced abortion

- History of prior pregnancy with abnormal placentation

- In primigravida, endometriosis and assisted conception have been associated.

Complications in these cases include - antepartum and post-partum hemorrhage, bowel and/or bladder injury, caesarean hysterectomy, preterm delivery, maternal and fetal morbidity and mortality.

Surgical interference in these cases requires a competent multidisciplinary team including urologist, vascular surgeon and possibly interventional radiologist for possible selective artery embolization. An efficient team capable for managing possible complicated situations will reduce mortality and morbidity to the least possible.

In spite of the significant improvement in obstetric care and management and modern transfusion service, antepartum and postpartum bleeding continues to be an essential cause of maternal morbidity and mortality.

The aims of the study were to find aetiological factors for abnormal placentation when possible; to know the various clinical presentation; to study the factors responsible for maternal morbidity and mortality; to study neonatal outcome in these cases.

\section{METHODS}

This was a retrospective study conducted in the department of obstetrics and gynecology, Sir Sayaji Hospital, Baroda for a period of 2 years from January 2018 to December 2019.

\section{Inclusion criteria}

All cases of placenta previa, morbidly adherent placenta and vasa previa diagnosed by clinical and ultrasonography admitted during the study period. Gestational age $>28$ weeks were included in this study.

\section{Exclusion criteria}

Cases with gestational age $<28$ weeks, and other causes of antepartum hemorrhage were excluded from the study.

All cases of abnormal placentation diagnosed by clinical or ultrasonography were included in the study. All case records were obtained from medical record section, SSGH, Baroda and were carefully analyzed to find out the prevalence, risk factors attributing to etiology, various clinical presentation, and type of placenta previa and morbidly adherent placenta, intra-operative findings, management, perinatal and maternal outcome.

\section{RESULTS}

In this study, out of 142 patients, $49.2 \%$ patient were in 20-25 years age group. $35.9 \%$ were in 26-30 years age group as depicted in Table 1.

As per Table 2, Out of 142 patients, 53 patients (37.3\%) were of $2^{\text {nd }}$ gravida, out of which most had previous section. $3^{\text {rd }}$ gravida or more comprised $42.8 \%$. This group has patients who had more than 1 uterine scar.

According to Table 3, the most common abnormality encountered was placenta previa type I (35.9\%). Morbidly adherent placenta comprised $4.2 \%$. Single case of vasa previa was documented with velamentous placenta. 
Table 1: Distribution according to maternal age.

\begin{tabular}{|lll|}
\hline Age (years) & No. of cases & Percentage \\
\hline $\mathbf{2 0}$ & 9 & 6.3 \\
\hline $\mathbf{2 0 - 2 5}$ & 70 & 49.2 \\
\hline $\mathbf{2 6 - 3 0}$ & 51 & 35.9 \\
\hline$>\mathbf{3 0}$ & 12 & 8.5 \\
\hline
\end{tabular}

Table 2: Incidence of abnormal placentation with respect to gravida.

\begin{tabular}{|lll|}
\hline Gravida & No. of cases & Percentage \\
\hline Primigravida & 28 & 19.7 \\
\hline $\mathbf{2}^{\text {nd }}$ & 53 & 37.3 \\
\hline $\mathbf{3}^{\text {rd }}$ & 41 & 28.8 \\
\hline $\mathbf{4}^{\text {th }}$ and more & 20 & 14.0 \\
\hline
\end{tabular}

Table 3: Incidence in relation to type of placental localization.

\begin{tabular}{|lll|}
\hline Type & No. of cases & Percentage \\
\hline Type 1 low lying & 51 & 35.9 \\
\hline Type 2 marginal & 33 & 23.2 \\
\hline Type 3 incomplete & 22 & 15.4 \\
\hline Type 4 complete & 29 & 20.4 \\
\hline Adherent placenta & 6 & 4.2 \\
\hline Accreta & 3 & 2.1 \\
\hline Increta & 1 & 0.7 \\
\hline Percreta & 2 & 1.4 \\
\hline Vasa previa & 1 & 0.7 \\
\hline
\end{tabular}

Table 4: Incidence of various types of presentation.

\begin{tabular}{|lll|}
\hline Presentation & No. of cases & Percentage \\
\hline Cephalic & 119 & 83.8 \\
\hline Breech & 11 & 7.7 \\
\hline Transverse & 9 & 6.3 \\
\hline Unstable lie & 3 & 2.1 \\
\hline
\end{tabular}

As per Table 4, $83.8 \%$ patients had cephalic presentation and $16.2 \%$ patients had malpresentation.

Table 5: Incidence of abnormal placentation with respect to period of gestation.

\begin{tabular}{|lll|}
\hline Gestational age & No. of cases & Percentage \\
\hline 28-33 weeks & 38 & 26.7 \\
\hline 34-37 weeks & 40 & 28.1 \\
\hline 38-42 weeks & 64 & 45.0 \\
\hline
\end{tabular}

Out of 142 patients, 64 patients (45\%) delivered at term, 78 patients $(55 \%)$ delivered at preterm. Most of the babies delivered in these cases were of $2-2.5 \mathrm{~kg}$ in weight. $26.7 \%$ low birthweight babies required support; perinatal mortality was $15.4 \%$ (22 cases) with weight of around $1-1.2 \mathrm{~kg}$. out of these the number of male children were $81(57 \%)$.
The mode of delivery was determined on various factors. Normal vaginal delivery was achieved in 44 patients (31\%) while 98 patients $(69 \%)$ had to undergo caesarean section of which $49 \%$ was emergency and $20 \%$ was elective termination.

Table 6: Maternal complication.

\begin{tabular}{|lll|}
\hline Complication & No. of cases & Percentage \\
\hline Atonic PPH & 12 & 8.4 \\
\hline Hysterectomy & 8 & 5.6 \\
\hline Hemorrhagic shock & 18 & 12.6 \\
\hline Bladder injury & 2 & 1.4 \\
\hline Bowel injury & 0 & 0 \\
\hline
\end{tabular}

The complication was seen as per Table $6,12.6 \%$ patients had haemorrhagic shock due to severe blood loss. Most of the patients required more than 1 blood transfusion $(68.9 \%) .12 .6 \%$ patients did not require any transfusion. 3 or more transfusions were required by $26.7 \%$. The cases of morbidly adherent placenta (PAS) were managed by hysterectomy.

\section{DISCUSSION}

The present study was undertaken to evaluate the cases of abnormal placentation, its clinical presentation and fetomaternal outcome in patients admitted during January 2017 to December 2018.

Abnormal placentation refers to abnormal placental attachment to the uterine wall with regard to site and depth. Placenta previa is placenta attached to lower uterine segment. PAS characterized by invasion of trophoblast into the myometrium. The appearance of PAS after major changes in the caesarean surgical techniques is highly suggestive of a direct relationship between prior uterine surgery and abnormal placentation. Several hypotheses to explain the abnormal placentation include a primary defect of the trophoblast function, a secondary basalis defect due to a failure of normal decidualization and more recently an abnormal vascularization and tissue oxygenation of the scar area. ${ }^{6}$

In this study, prevalence of abnormal placentation was 142 cases out of 16,844 deliveries accounting for $0.8 \%$. Placenta previa accounted for 135 cases, 6 cases (4.2\%) were of morbidly adherent placenta, 1 case $(0.7 \%)$ reported of vasa previa.

India is a country where women enter marriage at a very early age which leads to early age pregnancy. The rise of caesarean section in this era has led to increase in placentation abnormalities. 70 patients $(49.2 \%)$ were in $20-25$ years age group followed by 51 patients $(35.9 \%)$ in 26-30 years age group.

Out of 142 patients, 53 patients $(37.3 \%)$ were of 2 nd gravida, out of which 49 patients $(34.5 \%)$ had previous 
section. Multiparous patients comprised 61 cases (42.8\%), most patients (38 patients) in this group had more than 2 previous caesarean section. Studies have found that the strongest risk factor for placenta previa is a prior caesarean section which suggests that there is a failure of decidualization in the area of a previous uterine scar. Ultrasound, being the choice of investigative modality have shown that large and deep myometrial defects are often associated with absence of reepithelialization of the scar area. These findings support the concept of a primary deciduo-myometrium defect in placenta accreta, exposing the myometrium and its vasculature below the junctional zone to the migrating trophoblast. The loss of this normal plane of cleavage and the excessive vascular remodeling of the radial and arcuate arteries can explain the in-vivo findings and the clinical consequence of placenta accreta.

The most common abnormality encountered was placenta previa type I $(35.9 \%)$. Morbidly adherent placenta comprised 6 cases $(4.2 \%)$. 1 case $(0.7 \%)$ of vasa previa was documented which was with velamentous placenta.

Malpresentation in placenta previa is more common as the lower part of pelvis is occupied by placenta. In this study, (83.8\%) 119 patient had cephalic presentation and $(16.2 \%)$ were non cephalic presentation.

A total $64(45 \%)$ patients delivered at term, 78 patients (55\%) delivered at preterm. The patients diagnosed at antenatal period were admitted and electively delivered at completion of 37 weeks. Out of these male children were $81(57 \%)$.

A total $69 \%$ patients required operative intervention; emergency caesarean was done in $49 \%$ which is similar to study carried out by Vaishali et al where emergency section was done in $54.5 \%$. Elective termination of pregnancy was done in $20 \%$. For effective management, planned procedure should be followed as good outcomes depend on prenatal diagnosis and caesarean delivery before the membranes rupture. ${ }^{7}$

Most of the babies delivered in these cases were of 2-2.5 $\mathrm{kg}$ in weight. $26.7 \%$ low birthweight babies required support; perinatal mortality was $15.4 \%$ (22 cases) who weighed between 1-1.2 kg. out of these 22, 14 cases were of complete placenta previa (type 4) and 8 cases were of (type 3) incomplete placenta.

The most dreaded and common complication was hemorrhagic shock due to severe blood loss in 18 cases $(12.6 \%)$ followed by atonic PPH in 12 cases $(8.4 \%)$. Atonic PPH was managed by medical and surgical intervention and 2 cases required hysterectomy.

Peripartum hysterectomy was done in 8 cases $(5.6 \%)$, out of which 6 was done for morbidly adherent placenta and 2 for atonic PPH.
Due to haemorrhage being the most common and feared complication, blood transfusion was necessary in most of the patients. 1 blood was transfused in 26 patients $(68.9 \%), 60$ cases $(42.2 \%)$ required 2 blood transfusions, 38 cases $(26.7 \%)$ required 3 or more than 3 blood units, (12.6\%) 18 patients did not require any transfusion, these patients were diagnosed antenatally managed conservatively.

\section{CONCLUSION}

The disorders of placental implantation group include many entities which have in common a decreased or absent decidualized endometrium resulting in abnormal implantation and increased placental adhesion.

Managing a case of placenta previa or placenta accreta during pregnancy poses a great challenge to every obstetrician in present day obstetrics due its increased risk of maternal and perinatal complication.

Thus, good antenatal care including more frequent antenatal check-ups, correction of anemia during antenatal period, anticipating the complications in consultation with senior obstetrician, educating the patient's regarding the complications like prematurity, need for blood transfusions and its products and rarely hysterectomy and taking the paediatrician help will definitely reduce the perinatal complications associated with it. A multidisciplinary approach is the best way to reduce morbidity and mortality.

\section{ACKNOWLEDGMENTS}

Authors would like to thanks all seniors, juniors, colleagues, staff who have helped to accomplish the study.

Funding: No funding sources Conflict of interest: None declared

Ethical approval: Not required

\section{REFERENCES}

1. Bauer ST, Bonanno C. Abnormal placentation. In Seminars in Perinatology. WB Saunders.; 2009;33(2):88-96.

2. Cresswell JA, Ronsmans C, Calvert C, Filippi V. Prevalence of placenta praevia by world region: a systematic review and meta-analysis. Trop Med Inter Health. 2013;18(6):712-24.

3. Jauniaux E, Grønbeck L, Bunce C, Langhoff-Roos J, Collins SL. Epidemiology of placenta previa accreta: a systematic review and meta-analysis. BMJ Open. 2019;9(11):e031193.

4. Ruiter L, Kok N, Limpens J, Derks JB, de Graaf IM, Mol BWJ, et al. Incidence of and risk indicators for vasa praevia: a systematic review. Int $\mathrm{J}$ Obstet Gynaecol. 2016;123(8):1278-87. 
5. Satija B, Kumar S, Wadhwa L, Gupta T, Kohli S, Chandoke R, et al. Utility of ultrasound and magnetic resonance imaging in prenatal diagnosis of placenta accreta: a prospective study. Indian J Radiol Imag. 2015;25(4):464

6. Jauniaux E, Jurkovic D. Placenta accreta: Pathogenesis of a 20th century iatrogenic uterine disease. Placenta. 2012;33(4):244-51.
7. Oyelese Y, Smulian JC. Placenta previa, placenta accreta, and vasa previa. Obstet Gynecol. 2006;107(4):927-41.

Cite this article as: Sharma SS, Gokhale AV, Agarwal S, Hindocha J, Kondhia A. Abnormal placentation at a tertiary care centre. Int J Reprod Contracept Obstet Gynecol 2020;9:3770-4. 